\title{
DESIGN INCLUSIVO: CRIAÇÃO DE ESTAMPAS EM PROL DA INCLUSÃO SOCIAL
}

\author{
Maiara Sant'ana Pacheco \\ Faculdade SATC \\ maraiasantp@gmail.com \\ Diego Piovesan Medeiros \\ Faculdade SATC/ UFSC \\ diego.piovesan@gmail.com \\ Marília Matos Gonçalves \\ CCE/ UFSC \\ marilinhamt@gmail.com
}

Resumo: Este artigo tem como objetivo criar uma linha de camisetas que auxiliem na inclusão social de deficientes visuais. Para isso foram abordados assuntos como design de superfície, superfície têxtil, e design universal. Além disso, uma metodologia de projeto foi elaborada de forma a se encaixar ao conceito do projeto proposto e aos ideais de produção requeridos pelo ramo do vestuário. Por fim, para confirmar e verificar a qualidade do projeto desenvolvido, foram realizadas entrevistas com dois perfis de público. 0 primeiro perfil composto por pessoas com deficiência visual total e parcial e o segundo por jovens sem nenhuma deficiência que costumam comprar camisetas diferenciadas.

Palavras-chave: Design; Inclusão; Desenho Universal; Moda; Deficiente Visual.

Abstract: This paper has objective to create a line of shirts that help the social inclusion of the visually impaired. For it matters as surface design, textile surface, and universal design were addressed. In addition, a design methodology was drafted to fit the concept of the proposed project and the ideal production required by the garment industry. Finally, to confirm and verify the quality of the project developed, interviews with two profiles were made public. The first section consists of people with full and partial visual impairment and the second by youngsters without disabilities who often buy shirts differentiated.

Keywords: Design, Inclusion, Universal Design, Fashion, Visual Disability. 


\section{INTRODUÇÃO}

O design possui a função de resolver problemas. Posiciona-se no mercado para agregar valor e identidade a marcas e projetos. Sendo assim, design é uma profissão que trabalha com a criação e desenvolvimento de projetos e estratégias que solucionem necessidades específicas. Podendo ser relacionadas a algo que esteja em falta no mercado ou que irá agregar algum valor de cunho social e significativo.

Essas necessidades surgem de empresas dos mais variados segmentos da indústria e serviços, incluindo o social. Dentre esses polos onde o design está inserido, a indústria têxtil faz um papel importante na geração de produtos gráficos relacionados à moda. Porém, este cenário se baseia apenas no visual, esquecendo de conceitos importantes como funcionalidade e usabilidade. Esses ideais são indispensáveis durante a projetação de peças que possam ser utilizadas por públicos diversos. Diante desse conceito de pesquisa, existe a seguinte problemática: Será possível criar estampas que possibilitem a transmissão das mensagens de forma clara para todas as pessoas, inclusive as com deficiência visual?

Para responder a essa pergunta, este trabalho se propõe a criar estampas que atendam também ao público com deficiência visual e submetê-las à avaliação de indivíduos com e sem problema de visão a fim de verificar se as peças criadas atendem satisfatoriamente a ambos os públicos. Com isso, espera-se incentivar uma maior inclusão social das pessoas com deficiência visual. Para o desenvolvimento deste trabalho, foi necessária a definição das etapas e dos tipos de pesquisa. Assim, os processos realizados para a coleta das informações utilizadas foram: a) pesquisa de caráter exploratório; b) pesquisa de procedimento bibliográfico; c) pesquisa de procedimento experimental; d) pesquisa de abordagem qualitativa.

Com isso, este artigo é dividido em três passos. O primeiro, com uma abordagem teórica visa apresentar alguns conceitos pertinentes a design de superfície e ao design universal. O segundo passo é a elaboração de dois protótipos, um para cada gênero. Com eles foi possível alcançar uma coleta de dados mais aprofundada, pois para cada sexo havia um protótipo específico. Esse processo intensificou os resultados da terceira etapa do artigo, as validações com os públicos, facilitando a análise qualitativa, pois as emoções e a opiniões dos participantes ficaram bem definidas durante as etapas de perguntas.

As entrevistas foram realizadas entre os dias cinco e seis de novembro de $2012 \mathrm{em}$ Criciúma, Santa Catarina. Os entrevistados pertencentes ao perfil de público com deficiência visual, total ou parcial, foram selecionados por intermédio e autorização de Valentim Nesi, presidente da ADVISUL (Associação dos Deficientes Visual do Sul).

\section{DESIGN DE SUPERFÍCIE}

Analisando o perfil brasileiro, Rüthschilling (2008) define o designer de superfície como um profissional que desenvolve texturas visuais e táteis, visando a soluções estéticas e funcionais para cada contexto sociocultural e dentro de cada possibilidade de produção.

Rubim (2005, p.35) acrescenta: “O Design de Superfície pode ser representado pelas mais diversas formas, desde que aceitemos que qualquer superfície pode receber um projeto". As principais aplicações para o design de superfície, ainda segundo a autora, são: têxtil, cerâmica, porcelana, plástico e papel. O vidro e o emborrachado são 
considerados interessantes, porém são pouco explorados. A definição do material é um dos pontos primordiais para o desenvolvimento do projeto de design de superfície.

É bom ressaltar que todo projeto de design de superfície possui uma grande base de estudos. Rüthschilling (2008) afirma que o profissional dessa área deve levar em conta a adequação do projeto diante dos vários processos de fabricação e dos materiais disponíveis. É necessário também um estudo socioeconômico e cultural dos usuários e futuros consumidores do produto, além de levar em conta as limitações financeiras e tecnológicas das empresas que bancarão e/ou produzirão o projeto.

O Design "não é uma regra universal de configuração, mas uma ação interpretativa, criadora, que permite diversas formas de expressão" (BONFIM, 1999, p.152 apud NAVALON, 2008, p. 16). Daí a possibilidade de aproximações e distanciamentos entre as diferentes áreas do Design, pois, como bem argumenta Navalon (2008), a atividade de design pode ser comparada a construção de um tecido. É necessária a definição das interconexões estabelecidas entre o designer (trama), usuário (urdume) e o seu desejo (fio). Quando estes se entrelaçam e se interconectam, o tecido é configurado. E o segredo para tamanha variação nas áreas de atuação é que existem muitas maneiras de compor essas interconexões.

E dentre as áreas de trabalho no design de superfície, o setor têxtil é o que possui maiores subdivisões e possibilidades. O tecido disponibiliza uma gama de aplicações muito extensa. Rubim (2005) destaca os tecidos que já são projetados em sua própria estrutura, modelados de acordo com sua trama. Segundo a autora, no desenvolvimento de um projeto para a trama de um tecido, o profissional deve possuir conhecimentos específicos, muitas vezes adquiridos dentro das próprias fábricas, afinal, grande parte da indústria da moda produz suas próprias malharias.

Segundo Navalon (2008), as características e nomenclaturas dos tecidos são tantas quanto às possibilidades de configurações. Ruthschilling (2008) descreve o ramo têxtil como a área de produtos elaborados por meio de fibras, abrangendo todos os tipos de tecidos e não tecidos construídos a partir de diferentes formas de entrelaçamento de fios. A autora aponta quatro principais, sendo elas a tecelagem, malharia, jacquard e tapeçaria.

Estamparia é o processo de impressão de estampas (desenhos desenvolvidos a partir de processos técnicos) sobre o tecido. (RUBIM, 2005; RÜTHSCHILLING, 2008). A estampa é parte fundamental do design de uma peça. Seivewright (2009) informa que normalmente é por meio dela que se costuma ilustrar e mostrar uma determinada cartela de cores. Além disso, a partir dela é possível mostrar temas e influências sofridas pelo designer durante o desenvolvimento do projeto. A estampa pode ser localizada, uma repetição do tecido como um todo, conhecida como rapport, ou projetada para ser inserida em partes específicas de uma peça, para isto elas requerem conhecimentos técnicos do designer (SEIVEWRIGHT, 2009; RUBIM 2005).

Afirma Rubim (2005), que quando se é possível trabalhar com um cliente que aceite novidades, o mercado pode apresentar um campo de criação infinito. Nesse sentido, "[...] o design que busca ser óbvio, compreendido com facilidade e exatamente igual ao que foi projetado, implica a diminuição do espaço das interpretações alternativas e da possibilidade de agir de forma diferente" (REDSTRÖM, 2005 apud RÜTHCHILLING, 2008, p. 47). 


\section{DESIGN UNIVERSAL}

O desenho universal possui a função de conceber produtos, equipamentos, interiores e exteriores de edifícios, sistemas de transportes, áreas urbanas, tecnologias da informação e todo tipo de comunicação, de uma forma mais acessível e utilizável por todos os usuários, independente de gênero, etnia, saúde, deficiência ou qualquer outro fator existente. (PREISER, 2010).

Segundo Prado, Lopes e Ornstein (2010), o desenho universal engloba variadas situações e padrões. Para ser possível atender essas necessidades, é necessário reduzir o esforço na execução de determinada tarefa ou ambientes. De acordo com o estudo desenvolvido pelo Design for All Foundation, relatado por Ferrés (2005), um quinto da população mundial tem dificuldade para realizar as atividades domésticas, o que indica que parte desse problema está na dificuldade estabelecida pelo local e objetos ao nosso redor. Cegos, surdos, mudos, paraplégicos, pessoas com falta de um membro, daltônicos, idosos, ou até mesmo pessoas com problemas passageiros como membros engessados, crianças de colo e mulheres grávidas têm o direito de possuir a mesma usabilidade de locais e objetos que os demais jovens saudáveis (FERRÉS, 2005).

A inclusão social, para Guimarães (2010), nada mais é que o compartilhamento de recursos e ambientes acessíveis por todos, é pensar nas pessoas com deficiência, com problemas de mobilidade reduzida, orientação direcional, entre outros. Para o desenvolvimento de bons produtos voltados à área do design inclusivo, Ferrés (2005) acredita que apenas pesquisas teóricas e embasamentos técnicos não resultarão em um produto de grande sucesso.

Dentre as várias deficiências que o design universal se preocupa na criação de novos produtos mais inclusivos, está a que afeta a comunicação. Barbosa e Albuquerque (2010) afirmam que os olhos e os ouvidos são nossos maiores receptores de informação, sendo assim, pessoas com deficiência auditiva e visual são as mais afetadas em relação ao sistema de comunicação.

\subsection{Sistema Braille}

O braille é uma forma de leitura e escrita em relevo, segundo Canejo (2005), ele contém em seu sistema alfabético sessenta e quatro símbolos resultantes da combinação de seis pontos dispostos em posições diferentes. Os pontos são distribuídos em três colunas que servem como base estrutural.

Santos (2003) afirma que o sistema braille é composto de sessenta e três sinais formados por pontos distribuídos a partir do conjunto matricial $=(123456)$. Segundo a autora os pontos são numerados de cima para baixo, da esquerda para a direita, sendo assim a primeira coluna contém os números 1, 2 e 3, organizados de cima para baixo, e na segunda coluna os números 4,5 e 6, também organizados de cima para baixo.

\section{METODOLOGIA PROJETUAL}

O método de projeto consiste em uma série de operações necessárias e organizadas em ordem lógica, baseada normalmente na experiência. Munari (2008) explica que o objetivo de definir uma metodologia é alcançar o melhor resultado em menor tempo e com menor esforço.

Navalon (2008) corrobora afirmando que cada designer, mediante a sua realidade de criação, deve estabelecer um método de projeto e pesquisa, este pode ser um método próprio e ser modificado a cada novo projeto. Para a autora o mais importante é possuir o 
entendimento total das informações e suas conexões, sendo assim será possível identificar suas relações com o que está sendo proposto no mercado produtivo e então criar algo inovador. A metodologia projetual utilizada neste projeto foi baseada nos conceitos de metodologia linear de Munari (2008) e nas idealizações de produção de vestuário apresentadas por Navalon (2008).

Primeiramente foi identificado o problema bruto do projeto a ser desenvolvido: Como criar uma linha de camisetas para deficientes visuais? Logo após, foi definido o problema de maneira mais refinada; Afinal foi percebido que o verdadeiro problema era criar algo que pudesse ser usado por todas as pessoas, inclusive pelos deficientes visuais, para então poder gerar o fator da inclusão social e não criar um produto que fosse apenas usado pelos deficientes. Com isso, os subproblemas foram avaliados, como gerar essa inclusão social, que materiais utilizar na confecção das camisetas, como desenvolver algo diferenciado para os deficientes, como interagir o sentido do tato a uma estampa, além da estampa seria necessário ou não o desenvolvimento de uma etiqueta especial, entre outros.

Tendo o problema e seus componentes já definidos, foi iniciada a parte da coleta de dados. Somente após essa etapa foi possível passar para a etapa da análise de dados. Estes dados fazem parte da fundamentação teórica e foram coletados ao longo do procedimento bibliográfico. Logo, com os dados e sua análise em mãos, a parte criativa teve início. As informações coletadas disponibilizaram uma criação segura, pois todos os dados necessários estavam disponíveis. Diante disso, foi dado início a etapa do desenho de construção, que para este projeto é referente à criação das estampas.

Para o processo de desenvolvimento das estampas foram utilizadas etapas de criação, essas etapas são baseadas no processo de criação de moda defendido por Navalon (2008). Por meio dele, foram desenvolvidas duas estampas, uma para a camiseta do sexo feminino e outra para a camiseta do masculino, além de já serem definidas as áreas de bordado para cada camiseta. Com isso, nessa etapa ficou comprovado que o bordado poderia ser feito normalmente acima de uma área estampada por meio da serigrafia, da sublimação ou do transfer.

A próxima etapa, referente à experimentação, foi o momento de testar o que técnicos nas áreas específicas de produção afirmaram funcionar. Primeiramente foram enviadas as camisetas para uma empresa de transfer, após um dia elas foram entregues com as artes das estampas desenvolvidas aplicadas. Por esta metodologia ser uma adaptação da desenvolvida por Munari (2008), algumas diferenças serão identificadas. Para esta metodologia, a solução foi encontrada mediante o sucesso da experimentação e da criação do protótipo. Sendo que a próxima etapa foi à verificação da qualidade e do sucesso do projeto desenvolvido. Com as respostas obtidas nas entrevistas realizadas durante a experimentação, foi possível então analisar a quão válida foi à solução criada.

\subsection{ADVISUL}

A ADVISUL, Associação do Deficiente Visual do Sul, foi inaugurada dia 25 de novembro de 1982, após muita batalha por parte de Valentim Nesi, deficiente visual, natural da região de Criciúma/SC. Quem relata brevemente a história da associação é Minervina Nesi, esposa de Valentim e também deficiente, porém física.

Atualmente a ADVISUL possui em média 145 associados, porém possuem apenas dezessete alunos. Isso é devido a alguns fatores como espaço reduzido, número não suficiente de professores e a necessidade de atenção individual que cada aluno precisa, 
pois o acompanhamento deve ser feito de modo integral. Devido às questões apresentadas e à própria dificuldade da língua Braille, a idade mínima para se tornar um associado é de 14 anos, antes disso o acompanhamento é feito pelo SAED (Serviço de Apoio ao Estudante com Deficiência). A estrutura física da associação se localiza no bairro Próspera, Rua São Sebastião, no 367 na cidade de Criciúma/SC, Brasil.

\section{ESTAMPAS TÁTEIS}

No projeto desenvolvido nesta pesquisa, a harmonia visual possui uma prioridade secundária, não esquecida ou feita de qualquer forma, apenas não sendo o ponto principal do projeto. É o bordado que possuirá a prioridade de criação, ele acompanhará e transmitirá a mensagem existente na estampa, ou seja, não terá apenas a função de beleza, mas também, e principalmente, a de agente de informação.

A elaboração das etapas teve como base alguns processos considerados por Navalon (2008) durante a criação do design de moda. O processo foi moldado para melhor atender as principais: Definir tema e/ou tendência das estampas; Realizar pesquisas e coletar as informações; Elaborar a ideia da estampa dentro do tema escolhido; Organizar as referências visuais que serão utilizadas; Escolher os elementos principais e definir as cores; Desenhar rascunhos e redesenhar os elementos; Criar a frase que será inserida em braile por meio do bordado; Definir como e onde ficarão os bordados; Analisar se a estampa e o bordado estão coerentes entre si; Finalizar a estampa.

\subsection{Mosaic Skull: Estampa Masculina}

Com a tendência de moda e as etapas de elaboração da estampa definidas, segue a busca, dentro da moda urbana atual, por uma ideia interessante a ser desenvolvida. Durante a pesquisa visual sobre estampas já existentes no mercado e que estão sendo utilizadas nas ruas, além da pesquisa sobre assuntos que sejam abordados pela moda urbana, a caveira se realçou como um dos temas mais explorados. É interessante perceber a variedade de aplicações possíveis a partir desse conceito, tendo como ênfase a construção e/ou interação da imagem da caveira com formas geométricas básicas. Durante a coleta de dados foi possível já definir o conceito central da estampa realizada. O painel de referência visual foi construído com imagens coletadas dos seguintes elementos escolhidos: a) caveira; b) formas geométricas, preferencialmente o triângulo. Para não possuir um impacto tão agressivo, a intenção é desenvolver uma estampa que remeta à forma da caveira, porém de maneira subliminar. As cores utilizadas na estampa serão o amarelo puro e o preto.

O processo de construção da estampa foi realizado no programa de vetorização Adobe Illustrator. A imagem do rascunho foi inserida em uma página em branco do software, logo após a designer iniciou a etapa em que redesenhou a arte elaborada no rascunho. Com a ilustração do rascunho completamente redesenha, foi percebida a necessidade da modificação da arte, pois a proposta de transmitir subliminarmente a imagem da caveira não havia sido alcançada.

Com os elementos dos triângulos já redesenhados e bem solucionados, optou-se por apenas modificar suas formas de aplicação e posicionamento. Após serem criados, diretamente no Illustrator, mais alguns modelos de estampa, a estampa final foi definida. Composta de variações do elemento triângulo, posicionados da melhor maneira para 
poder formar a imagem da caveira subliminarmente. Um verdadeiro mosaico de triângulos (fig. 1).

Após a estampa estar pronta teve início à etapa de definição do bordado e da criação da frase a ser transmitida pela linguagem braile. O formato da caveira não será bordado, apenas serão bordados os contornos dos principais triângulos, porém, para poder compensar o fato de os deficientes visuais não conseguirem identificar a imagem da caveira, foi determinado que o conceito será transmitido por meio do braile. A frase ficará próxima ao topo do maior triângulo, ao lado direto, ela será: "Mosaico de triângulos". A frase foi traduzida para a linguagem braile com o auxílio do site Infopédia. No site há uma página com a função de traduzir os textos do português para o braile, automaticamente, além de explicar as informações básicas da construção do texto. Todas as palavras e frases utilizadas no projeto foram traduzidas por meio desse site.
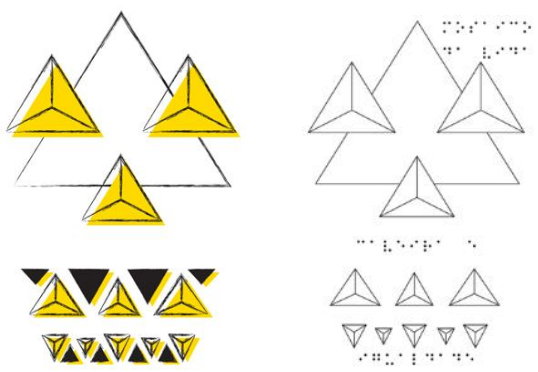

Figura 1 - Arte da estampa e desenho do bordado.

Fonte: Elaborado pelos autores, com base na pesquisa.

Após a chamada ser escolhida, traduzida e posicionada, foram escolhidas duas palavras soltas, "Caveira" e "Igualdade", para complementar ainda mais a estampa. As palavras foram inseridas no meio da estampa, sendo que a primeira palavra em braile, inserida logo acima a primeira carreira de triângulos (que formam os dentes superiores) significa caveira. A segunda palavra em braile, posicionada abaixo da segunda carreira de triângulos (que formam os dentes inferiores) significa igualdade.

Primeiramente foi transferida, sobre o tecido da camisa, a arte definida para a estampa, logo após foram bordados o desenho, a frase inicial e as duas palavras soltas. A união desses dois processos de produção deu origem à primeira estampa tátil desenvolvida por meio dos estudos levantados por este projeto (fig. 2).

Figura 2 - Estampa Tátil - Mosaic Skull.

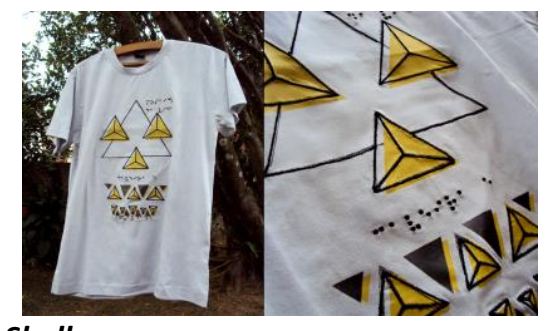

Fonte: Elaborado pelos autores, com base na pesquisa.

O resultado apresentado da primeira estampa tátil é uma amostra do que é possível ser feito por meio da junção de dois processos de produção comuns no meio da produção do vestuário. E faz refletir sobre a questão de como utilizamos os recursos que possuímos, mostrando que é possível ir além da ornamentação. 


\subsection{Tape-Love: Estampa Feminina}

Seguindo, novamente, o conceito de moda escolhido e as etapas de elaboração estabelecidas, a estampa feminina foi desenvolvida por meio da pesquisa visual de estampas já existentes no mercado atual, além, é claro, de assuntos abordados pela moda urbana. Durante a pesquisa, foi considerado interessante trabalhar com a releitura de algum elemento retrô, inserindo-o em um conceito lúdico e/ou atual.

O elemento retrô escolhido para ser trabalhado foi a fita cassete, ou fita tape. Durante as pesquisas foi visto que os elementos básicos como a cruz, a estrela e o coração também estão sendo muito explorados no ramo da moda. Outro elemento escolhido para ser trabalhado, porém como segundo plano na estampa, é o balão de ar em formato de coração, elemento comum em festas de aniversário e outros eventos mais românticos. Diante disso, a estampa será elaborada a partir das seguintes imagens: a) fita tape; b) desenho do coração; c) balão de ar em formato de coração.

Os elementos selecionados foram trabalhados com base na ideia utilizada pelo cantor Bruno Mars no clipe da música Just The Way You Are. No clipe, a fita vai se desenrolando do interior da fita tape e formando desenhos. A intenção é deixar a estampa feminina com uma identidade romântica, livre e adulta. Para poder distanciar o uso do coração do conceito infantil que o elemento pode transmitir, a arte será feita utilizando apenas dois tons, preto e vermelho. Desse modo, poderá ser gerada a ilusão de que a estampa foi fixada pelo processo de stencil. Abaixo segue o painel de referência visual (fig. 4), as imagens utilizadas foram coletadas ao longo da pesquisa e desenvolvimento do conceito da estampa.

Após ser definida a ideia central da estampa, escolher os elementos principais e elaborar o painel de referência visual, teve início a etapa de criação da estampa tátil. Ambas as partes, desenho da estampa e desenho do bordado, devem ser analisadas e desenvolvidas juntas, afinal elas devem transmitir a mesma mensagem ou o mais semelhante possível para assim formar uma unidade.

Para iniciar o processo de criação, foram feitos rascunhos a lápis em folhas em branco, foi a partir de um dos rascunhos que o aspecto visual da estampa foi definido.

Após essa etapa concluída, foram transferidas, para um arquivo novo no programa Illustrator, uma imagem de cada elemento, ou seja, da fita, do coração e do balão em formato de coração. Cada imagem foi redesenhada com traços simples, para transmitir melhor a ideia do stencil, e encaixadas entre si de acordo com a arte desenvolvida no rascunho. Após possuir o desenho de cada elemento, iniciou-se o processo de construção da ideia, ou seja, do coração sendo formado pela fita que sai da estrutura da fita. $O$ balão de ar em formato de coração, como já havia sido definido, foi utilizado em segundo plano, para dar uma riqueza a mais para a estampa (fig. 3).
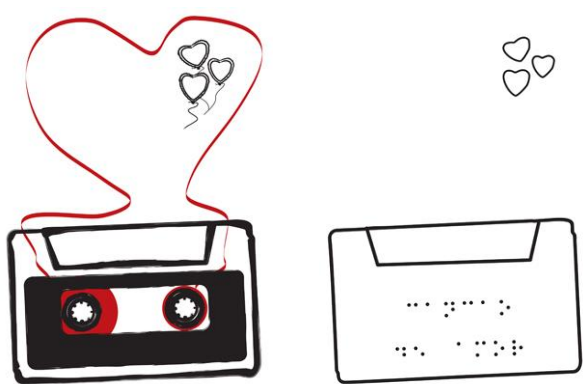

Figura 3 - Arte da estampa e desenho bordado. Fonte: Dos autores. 
O bordado será feito acima da estampa, ele estará interagindo e completando o conceito da arte com formas simples, porém explicativas. Sendo assim, foi definido que o bordado será feito no tom preto e estará contornando o formato de coração dos balões de ar que ficarão em um tamanho reduzido. O motivo para isso é deixar o formato dos corações de fácil acesso para o deficiente visual, pois quanto maior a forma, mais demorado será para eles identificarem o elemento através do tato.

Juntamente com o bordado dos corações, será bordada na linguagem braile a seguinte frase, "Canção de amor." A frase foi traduzida para a linguagem braile com o auxílio do site Infopédia. A frase será feita no local onde se costuma colar a etiqueta com as informações da fita. Com a união das duas etapas de produção, temos então a segunda estampa tátil desenvolvida (fig. 4).

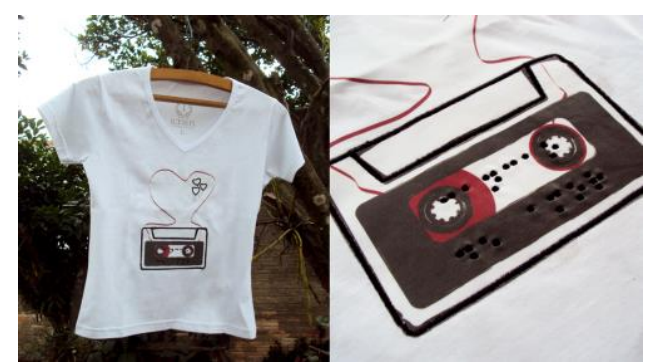

Figura 4 - Estampa Tátil - Tape-Love.

Fonte: Dos autores.

Por fim, a estampa apresenta um aspecto atrativo e simples, por possuir poucas cores e formatos bem definidos. A ideia de transparecer ter sido produzida por stencil foi alcançada e o bordado, ainda que existente, está mesclado com a estampa, para não possuir destaque e sim apenas completar a arte com, principalmente, a conotação de agente informativo.

\section{VALIDAÇÃO COM OS PÚBLICOS}

A aplicação das entrevistas ocorreu por meio da autorização de cada participante, sendo que estes leram e assinaram o termo de consentimento entregue antes da mesma. No caso dos entrevistados que pertencem a ADVISUL, quem se tornou responsável assinando o termo de consentimento foi o presidente da associação, o senhor Valentim Nesi, afinal não será citado o nome de nenhum dos participantes. Com isso a autorização do presidente se torna suficiente para a composição do estudo. As entrevistas foram realizadas separadamente com cada participante, para que assim a resposta e/ou reação de um não influenciasse os outros entrevistados. Inicialmente, foram entrevistadas pessoas que pertencem ao perfil de público com deficiência visual total ou parcial. Todos os entrevistados desse perfil foram selecionados por intermédio da ADVISUL.

Por não possuírem um grande número de associados, foi possível, no dia marcado para a realização dos questionários, apenas entrevistar três pessoas do sexo masculino e três do sexo feminino, de diferentes idades. Em ambos os gêneros, duas possuíam deficiência visual total e uma baixa visão, ou seja, deficiência visual parcial. Logo, foi possível ter um total de seis entrevistados. Com base no número de entrevistados, foi considerado necessário entrevistar seis pessoas que pertencem ao perfil de público jovem sem nenhuma deficiência e que costumam comprar camisetas diferenciadas. Da mesma forma que o perfil anterior, foram entrevistadas três pessoas do sexo masculino e três do 
sexo feminino. A análise das entrevistas é baseada nos resultados obtidos pelo entrevistador durante a elaboração de cada pergunta.

\subsection{Análise da entrevista com o público com deficiência visual total ou parcial}

$\mathrm{Na}$ primeira etapa todas as respostas foram similares, sendo que nenhum participante possuiu dificuldade para sentir as texturas e diferenciar do tecido. $\mathrm{Na}$ entrevista com o sexo feminino foi mais fácil para as entrevistadas perceber que no local indicado na estampa da camiseta o relevo formava algum elemento. Duas das participantes até mesmo conseguiram identificar os três elementos como sendo corações. Na entrevista com o sexo masculino houve certa dificuldade quanto ao reconhecimento dos elementos, ou seja, dos triângulos. As linhas dos interiores dos triângulos atrapalharam no momento da identificação, além do fato de serem elementos maiores que os elementos da estampa feminina, o que dificultou a rápida assimilação, pois o tempo necessário para sentir todo o contorno era maior.

Entre todos os seis entrevistados, somando ambos os gêneros, apenas um considerou que as bolinhas referentes aos pontos do símbolo braile estão muito próximas.

Na segunda etapa, após explicar o conceito do projeto, todos os entrevistados se mostraram mais entusiasmados. Dos seis entrevistados, os dois deficientes visuais parciais eram os únicos que não sabiam a linguagem braille e não responderam as duas primeiras perguntas da segunda etapa. Porém, ambos consideraram válida a proposta apresentada e afirmaram que comprariam camisetas com o conceito da estampa tátil.

Dos quatro entrevistados que possuem deficiência visual total, um ainda está iniciando os estudos do braile, sendo deste modo, não foi possível a leitura da frase escrita, apenas a identificação de alguns símbolos do alfabeto. Os demais entrevistados conseguiram identificar a linguagem braile no local indicado na estampa de ambas as camisetas e, até mesmo, ler as frases escritas, ainda que com certa dificuldade. Todos eles consideraram que o projeto auxilia na questão da inclusão social e afirmaram que comprariam uma camiseta com o conceito apresentado se tivessem a chance. Sendo assim, é possível afirmar que o resultado final das seis entrevistas realizadas com pessoas com deficiência visual foi positivo.

\subsection{Análise da entrevista com o público jovem sem nenhuma deficiência}

A entrevista com o público composto por pessoas jovens sem nenhuma deficiência e que costumam comprar camisetas diferenciadas foi realizada em quatro etapas. As quatro primeiras perguntas pertencem à primeira etapa, onde o participante estava vendado e não tinha conhecimento algum sobre o tema do projeto. As respostas, como na outra entrevista analisada, foram similares. Sendo que todos os participantes conseguiram sentir as texturas e diferenciar a mesma do tecido sem dificuldades.

A grande diferença nessa primeira etapa se deu na identificação dos elementos formados pelo bordado em cada camiseta. Na entrevista com o sexo feminino, nenhuma das entrevistadas conseguiu identificar os três elementos no local indicado como sendo corações, duas acharam que era círculos e/ou bolas e uma arriscou dizendo serem arabescos. Já na entrevista com o sexo masculino um dos entrevistados conseguiu identificar o formato do triângulo com as linhas no meio. Os outros dois participantes apenas afirmaram sentir algum formato, porém sem identificar o que seria. Na segunda etapa das entrevistas foram realizadas duas perguntas, os participantes ainda estavam 
vendados. Foi pedido para cada entrevistado que sua atenção fosse focada no local indicado pelo entrevistador e apenas um dos entrevistados não reconheceu.

Já sem a venda, os participantes responderam a mais três perguntas, agora já pertencentes à terceira etapa. Mesmo nesse ponto do questionário ainda não foi explicado aos participantes o conceito do projeto apresentado, pois agora seriam questionadas as questões estéticas do produto. Sendo assim, todos os seis entrevistados consideraram que o bordado atual não influenciou negativamente na estética da estampa apresentada. Apenas um adicionou que dependendo da forma de aplicação pode adicionar ainda mais beleza a peça ou não.

As duas únicas questões negativas levantadas sobre o projeto foram: a participante do sexo feminino afirmou não se sentir confortável com estampas que geram toque, pois esse fato a incomoda. Já o participante do sexo masculino avaliou a camada de fibra interna, necessária pela questão do bordado. Segundo ele, isso pode dar desconforto e ele não gosta de etiquetas e/ou outros elementos desse tipo.

Por fim, a quarta e última etapa é composta de apenas uma pergunta e é justamente nesse ponto final do questionário que o conceito do projeto é explicado aos participantes. Todos se mostraram receptivos e um tanto surpresos com a ideia do projeto, afirmando por fim que comprariam sim camisetas com o conceito da estampa tátil. O fato de ser um produto novo no mercado foi reconhecido por todos, sendo que um dos entrevistados analisou que caso lançada, a camiseta com estampa tátil se diferenciaria de maneira positiva das demais.

\section{CONSIDERAÇÕES FINAIS}

Com foco no conceito da inclusão social por meio do vestuário, as estampas desenvolvidas possuem como principal intenção o ideal de informar ao deficiente visual o que seria apenas gráfico no produto. A estampa tátil permite que o deficiente interaja e entenda o significado da estampa criada. Além de poder saber exatamente o que está vestindo e assim poder criar o seu estilo próprio e/ou acompanhar a moda. Foi por meio do bordado que se tornou possível a utilização do tato como meio sensorial. O tato é um dos sentidos mais bem desenvolvidos e utilizados pelos deficientes visuais, afinal, a leitura dos símbolos braille se dá por meio da utilização deste sentido.

De modo geral, a realização das entrevistas teve um resultado positivo, afirmando assim a qualidade do projeto proposto. Todos os entrevistados conseguiram sentir o relevo do bordado, diferenciaram bem a textura do bordado com a da trama da camiseta e alguns até mesmo identificaram os elementos que estavam sendo formados pelo bordado do seu contorno.

As entrevistas com pessoas sem nenhuma deficiência foram realizadas dias após a entrevista com os deficientes visuais, diante disso foi possível perceber quanto o tato dos deficientes é realmente mais apurado do que o tato de pessoas que ainda possuem a visão. A maioria, para não dizer todos, dos deficientes não apresentou nenhum nível de dificuldade no momento de responder se haviam ou não conseguido sentir as "bolinhas" separadamente. Já no caso das pessoas sem nenhuma deficiência, muitos de mostraram apreensivos e com dúvidas, mas afirmaram estar sentindo as "bolinhas".

Esta pesquisa é uma obra aberta e não termina com a conclusão deste texto, possibilitando outras pesquisas na área do design gráfico e de superfície, além de ser possível sua continuidade por meio da área da moda e do desenho universal. 


\section{REFERÊNCIAS}

BARBOSA, Maria Beatriz; ALBUQUERQUE, Roberta de Medeiros Arruda. Comunicação, Sinalização e Acessibilidade. In: PRADO, Adriana R. de Almeida; LOPES, Maria Elisabete; ORNSTEIN, Sheila Walbe. (Org.). Desenho universal: caminhos da acessibilidade no Brasil. São Paulo: Annablume, 2010. P. 279-290.

CANEJO, Elizabeth. Apostila Introdução ao Sistema Braille. Fundação de Apoio à Escola Técnica - FAETEC. Diretoria do Desenvolvimento da Educação - Gerência do Programa de Inclusão. Governo do Estado de Rio de Janeiro, 2005.

CONSTANT, Instituto Benjamin. Acessibilidade Brasil. Disponível em: < http://www.ibc.gov.br/>. Acesso em: 20 mai. 2012.

FERRÉS, M. Sofia Pérez. Design Inclusivo. Disponível em: <http://styx.nied.unicamp.br:8080/todosnos/acessibilidade/textos/design_inclusivo.html \#importancia>. Publicado em: 16 nov. 2005. Acesso em: 20 mai. 2012.

GUIMARÃES, Marcelo Pinto. O Ensino de Design Universal nas Universidades. In: PRADO, Adriana R. de Almeida; LOPES, Maria Elisabete; ORNSTEIN, Sheila Walbe. (Org.). Desenho universal: caminhos da acessibilidade no Brasil. São Paulo: Annablume, 2010. p. 45-55.

LOPES, Maria Elisabete; BURJATO, Ana Lucia Pinto de Faria. Ergonomia e Acessibilidade. In: PRADO, Adriana R. de Almeida; LOPES, Maria Elisabete; ORNSTEIN, Sheila Walbe. (Org.). Desenho universal: caminhos da acessibilidade no Brasil. São Paulo: Annablume, 2010. p. 69-79.

NAVALON, Eloize. Design de Moda: Interconexão Metodológica. 2008. 101f. Dissertação (Mestrado em Design) - Programa de Pós-graduação em Design. Universidade Anhembi Morumbi, São Paulo, 2008.

PRADO, Adriana Romeiro de Almeida; LOPES, Maria Elizabete; ORNSTEIN, Sheila Walbe. Apresentação: Trajetória da Acessibilidade no Brasil. In: PRADO, Adriana R. de Almeida; LOPES, Maria Elisabete; ORNSTEIN, Sheila Walbe. (Org.). Desenho universal: caminhos da acessibilidade no Brasil. São Paulo: Annablume, 2010. p. 9-17.

PREISER, Wolfgang F. E. Das Políticas Públicas à Prática Profissional e à Pesquisa de Avaliação de Desempenho Voltadas para o Desenho Universal. In: PRADO, Adriana R. de Almeida; LOPES, Maria Elisabete; ORNSTEIN, Sheila Walbe. (Org.). Desenho universal: caminhos da acessibilidade no Brasil. São Paulo: Annablume, 2010. p. 19-32.

RUBIM, Renata. Desenhando a Superfície. São Paulo: Edições Rosari, 2005.

RÜTHSCHILLING, Evelise Anicet. Design de Superfície. Porto Alegre: Ed. da UFRGS, 2008.

SANTOS FILHO, Gildo Magalhães dos. Construindo um Itinerário Histórico no Desenho Universal: A Normatização Nacional e Internacional da Acessibilidade. In: PRADO, Adriana R. de Almeida; LOPES, Maria Elisabete; ORNSTEIN, Sheila Walbe. (Org.). Desenho universal: caminhos da acessibilidade no Brasil. São Paulo: Annablume, 2010. p. 35-43.

SASSAKI, R. K. Inclusão: Construindo uma sociedade para todos. Rio de Janeiro: WVA, 1997. ACESSIBILIDADE BRASIL. O que é Acessibilidade? Disponível em: <http://www.acessobrasil.org.br/index.php?itemid=45>. Acesso em 20 mai. 2012.

SEIVEWRICHT, Simon. Fundamentos de Design de Moda: Pesquisa e Design. Porto Alegre: Editora Bookman, 2009. 